\title{
Avaliação de metais em esgoto bruto e tratado no município de Limeira (SP), empregando a técnica TXRF.
}

\section{Giovana Vieira Romita*, Felippe Benavente Canteras}

\begin{abstract}
Resumo
Limeira (SP) possui uma economia diversificada, com destaque no setor de jóias e folhados, com diversas indústrias galvânicas. Os efluentes gerados nas galvanoplastias são considerados uns dos mais tóxicos dentre os diversos ramos industriais, devido a presença de metais pesados. Grande parte dessa produção no município é de origem informal, resultando na ausência de tratamento dos efluentes e lançamentos irregulares na rede de esgoto. Nesse contexto, visando verificar a composição do efluente no município utilizou-se a técnica TXRF para detecção de metais no esgoto bruto e tratado em duas ETEs na cidade de Limeira, comparando as concentrações obtidas com a legislação vigente e verificando a influência do setor de joias e folheados na composição do esgoto da cidade.
\end{abstract}

\section{Palavras-chave:}

Efluente, Metais Pesados, Fluorescência de Raios-X.

\section{Introdução}

Devido a expansão urbana e a diversidade de atividades industriais, os efluentes possuem composições variadas, podendo apresentar diversos poluentes e substâncias tóxicas, dentre elas destacam-se os metais pesados, também denominados como elementos potencialmente tóxicos (EPTs).O município de Limeira situado no interior de São Paulo é conhecido pela sua produção de joias e bijuterias e é considerada a capital nacional da joia folheada. Um dos processos da fabricação de joias é o revestimento de peças (banho metálico) que geram efluentes contendo metais, sendo os mais utilizados o $\mathrm{Cr}$, $\mathrm{Ni}, \mathrm{Zn}, \mathrm{Cd}$ e Cu. Devido ao crescimento do setor na cidade, é comum o uso da mão-de-obra informal nos domicílios e a ocorrência de empresas clandestinas, levando a lançamentos irregulares sem nenhum tipo de tratamento prévio na rede de coleta de esgoto.

Levando em consideração o cenário descrito, através da aplicação da técnica de Fluorescência de Raios $X$ por Reflexão Total (TXRF) o projeto teve como objetivo principal avaliar as concentrações de metais nos esgotos bruto e tratado do município de Limeira, verificar a eficiência de duas ETEs da cidade na remoção de metais e verificar a influência do setor de joias e folheados na composição do esgoto da cidade.

\section{Resultados e Discussão}

As amostras foram digeridas através do método EPA 200.8. A técnica TXRF possibilitou a detecção dos metais de interesse, exceto $\mathrm{Cd}$ cujas concentrações ficaram abaixo do limite de detecção. Os padrões de lançamento de efluentes, estabelecidos pela CONAMA 430/2011, são $\mathrm{Cr}^{3+}=1,0 \mathrm{mg} / \mathrm{L}, \mathrm{Cr}^{6+}=0,1 \mathrm{mg} / \mathrm{L}, \mathrm{Ni}=2,0 \mathrm{mg} / \mathrm{L}, \mathrm{Zn}=$ $5,0 \mathrm{mg} / \mathrm{L}, \mathrm{Cu}$ dissolvido $=1,0 \mathrm{mg} / \mathrm{L}$. Nota-se pelos valores apresentados na tabela 1 que apenas o $\mathrm{Cu}$ ultrapassou os limites estabelecidos. Vale destacar que as técnicas detectaram os teores totais de $\mathrm{Cu}$, e não é possível afirmar que são representativas dos teores dissolvidos, porém são valores que podem servir de alerta a possíveis fontes de $\mathrm{Cu}$. O mesmo vale para $\mathrm{Cr}$, que pode ter ultrapassado valores para $\mathrm{Cr}^{6+}$, porém, por TXRF não é possível determinar a especiação química do $\mathrm{Cr}$ detectado. Nota-se que na ETE1 diversos teores de metais são maiores no efluente tratado do que no bruto, o que pode indicar um mal funcionamento da estação, com possível carreamento de lodo ou elevado tempo de detenção do mesmo.

Tabela 1. Concentrações (mg/L) dos EPTs detectados por TXRF em esgotos brutos e tratados de duas ETEs de Limeira.

\begin{tabular}{|c|c|c|c|c|c|c|c|}
\hline \multicolumn{2}{|c|}{ ETE 01} & $1^{\mathrm{a}}$ coleta & $2^{\mathrm{a}}$ coleta & $3^{\mathrm{a}}$ coleta & $4^{\mathrm{a}}$ coleta & $5^{\mathrm{a}}$ coleta & 6 a coleta \\
\hline \multirow{2}{*}{$\mathrm{Cr}$} & Bruto & 0,27 & 0,39 & 0,06 & 0,47 & 0,11 & 0,08 \\
\hline & Tratado & 0,21 & 0,02 & $<$ LMD & 0,28 & 0,18 & $<$ LMD \\
\hline \multirow{2}{*}{$\mathrm{Ni}$} & Bruto & 0,32 & 0,61 & 0,21 & 0,64 & 0,49 & 0,30 \\
\hline & Tratado & 1,14 & 0,56 & 0,71 & 0,81 & 0,26 & 0,28 \\
\hline \multirow{2}{*}{$\mathrm{Cu}$} & Bruto & 1,76 & 1,72 & 2,23 & 1,35 & 1,69 & 1,19 \\
\hline & Tratado & 1,90 & 1,49 & 2,47 & 2,31 & 0,92 & 0,72 \\
\hline \multirow{2}{*}{$\mathrm{Zn}$} & Bruto & 0,95 & 1,01 & 1,51 & 1,76 & 2,10 & 0,85 \\
\hline & Tratado & 1,29 & 1,34 & 1,33 & 1,72 & 0,80 & 0,52 \\
\hline \multicolumn{2}{|c|}{ ETE 02} & $1^{\mathrm{a}}$ coleta & $2^{\mathrm{a}}$ coleta & $3^{a}$ coleta & $4^{\mathrm{a}}$ coleta & $5^{a}$ coleta & 6a coleta \\
\hline \multirow{2}{*}{$\mathrm{Cr}$} & Bruto & 0,14 & 0,01 & 0,13 & 0,19 & 0,38 & - \\
\hline & Tratado & 0,04 & 0,11 & $<$ LMD & 0,07 & 0,15 & - \\
\hline \multirow{2}{*}{$\mathrm{Ni}$} & Bruto & 0,56 & $<$ LMD & 0,42 & 0,61 & 0,54 & - \\
\hline & Tratado & $<$ LMD & $<$ LMD & $<$ LMD & 0,15 & $<$ LMD & - \\
\hline \multirow{2}{*}{$\mathrm{Cu}$} & Bruto & 1,11 & 0,53 & 0,74 & 0,80 & 0,83 & - \\
\hline & Tratado & 0,47 & 0,16 & 0,20 & 0,36 & 0,27 & - \\
\hline \multirow{2}{*}{$\mathrm{Zn}$} & Bruto & 1,66 & 1,39 & 0,76 & 0,82 & 0,39 & - \\
\hline & Tratado & 0,57 & 0,51 & 0,31 & 0,53 & 0,49 & - \\
\hline
\end{tabular}

\section{Conclusões}

Dentre os metais utilizados na galvanoplastia, o $\mathrm{Cu}$ foi o único elemento que ultrapassou o valor máximo permitido, entretanto, não é possível afirmar que seja decorrente do setor de joias e folheados já que este metal considerado essencial é amplamente utilizado em outros setores como fabricação de moedas, fios elétricos, tubulações e encanamentos de água quente.

\section{Agradecimentos}

Agradecemos ao Conselho Nacional de Desenvolvimento Científico e Tecnológico (CNPq) pelo financiamento da pesquisa na modalidade de bolsa de Iniciação Científica. Ao Prof. Dr. Edgar Francisco Oliveira de Jesus (COPPE/UFRJ) pelas medidas de TXRF.

${ }^{1}$ BRASIL. Ministério do Meio Ambiente. CONAMA. Resolução no 430, de 13 de maio de 2011. Dispõe sobre as condições e padrões de lançamento de efluentes, complementa e altera a Resolução n 357, de 17 de março de 2005, do Conselho Nacional do Meio Ambiente-CONAMA. Diário Oficial da República Federativa do Brasil, Brasília, DF, n 92, de 16 de maio de 2011, p. 89. 